\title{
Design of College Teaching Quality Evaluation System Based on Cloud Platform
}

\author{
Jitong Zhang \\ School of Information Engineering, Zhengzhou University of Industrial Technology, Zhengzhou, Henan, \\ 451150, PR China
}

Keywords: colleges and universities; teaching quality; evaluation; Cloud platform

\begin{abstract}
According to the reform of teaching methods in modern colleges and universities, a B/S based teaching quality evaluation system is developed. According to the teaching practice of present colleges and universities, the system is evaluated on the basis of the network based on the cloud platform. The system mainly includes students' evaluation, feedback, peer review, leadership evaluation, teacher evaluation, daily inspection, collective and evaluation, instructor evaluation, teacher and student evaluation, and so on. It basically involves all the colleges and universities, and the main body of all teaching activities such as students, teachers, counselors, supervision, leadership and teaching materials form a completed evaluation system to realize multi-angle and multi-orientation evaluation, so that the evaluation can reflect the actual teaching quality and teaching level of a phase of the school.
\end{abstract}

\section{Introduction}

Teaching is the central task of a school. We must constantly improve the quality of teaching in order to cultivate qualified talents to meet the requirements of the new era. Classroom teaching is the most basic and core teaching link in the teaching of higher education. It is the most direct and most important form of education in school education. The quality of teaching and the quality of the teaching effect directly affect the quality of the training of the school. With the popularization of higher education, the importance of classroom teaching is becoming more and more important. Improving the quality of classroom teaching has become an urgent task for the reform of higher education.

Teaching quality evaluation is an important part of university management, an important factor affecting the development of schools, and an effective means to train teachers' teaching ability. The evaluation of teachers' teaching quality is a key problem in every school's management. Reasonable and fair evaluation method can not only reflect the basic situation of teachers' work in a comprehensive and fair manner, but also fully respect teachers' rights. It has an obvious incentive and guidance role in improving the quality of teaching and promoting the improvement of teaching level, and has a higher area in evaluating the quality of teaching teachers' classroom teaching. Degree and reliability. Students' evaluation of teaching is a way of teaching evaluation. It is also an important aspect of teachers' teaching quality evaluation. The purpose is to carry forward advantages, overcome shortcomings and avoid shortcomings, so as to improve the quality of teaching.

\section{Status Quo}

At present, colleges and universities basically have their own teaching quality supervision system. The traditional monitoring methods and monitoring methods are not good enough to meet the requirements of the new teaching quality evaluation under the "new engineering". At the same time, the traditional teaching evaluation system is not perfect and does not form an effective college study. Students, teachers and carriers are all included in a system to carry out effective evaluation and monitoring, which leads to the one-sided and inaccurate evaluation results, and can not truly reflect the actual teaching level of the school. It is urgently needed for a comprehensive 
and real effective teaching quality evaluation system that is suitable for every university to complete the system of effective teaching quality. In order to adapt to the reform of teaching methods and means in the new form, the real teaching quality of various colleges and universities can be effectively monitored, which really embodies the change of the teaching quality evaluation system and the means of evaluation. Thus promoting the improvement of the quality of teaching in Colleges and universities.

Through the above analysis, the existing evaluation system can either evaluate information teachers can not obtain, or the operation is complex, the workload is large, the reliability is poor, the efficiency is low and the evaluation information is not comprehensive enough.

Through the development of a set of teaching quality evaluation system for each college in Zhengzhou Institute of applied technology, the overall evaluation and quantitative assessment of the teachers and teaching classes in various departments are carried out according to the rules and requirements of the new form of university management. The results of the assessment can be checked for teachers or students, and the system can automatically take all the evaluation letters. The new system not only includes student evaluation, peer review, teacher evaluation, student information feedback, and system supervision, but also can collect and count the evaluation of each teacher in a variety of ways, and can also teach quantitative evaluation information. Teachers, classes and grades are collected. It provides a scientific basis for the decision-making of the leadership. The new system also greatly reduces the workload and the complexity of the operation of the staff, to a great extent, improve the work efficiency, and then promote the improvement of teachers' teaching quality.

The system is first applied in Zhengzhou Institute of industrial application technology. It can be applied to all universities in the cloud platform, and it can be used in universities or colleges nationwide. In order to improve the evaluation methods and means of teaching quality in Colleges and universities, improve the efficiency of evaluation and the scientificity and practicability of the evaluation results, the system can further use the comprehensive comparison of the evaluation information of colleges and universities in the whole province to analyze the teaching quality of universities and colleges. The results can also be analyzed for the large data system and the teaching of colleges and universities in the province. To analyze, evaluate or predict the quality of learning and improve the use value of data.

\section{System Function}

Through the development of a set of teaching quality evaluation system for every college in Zhengzhou Institute of applied technology, the overall evaluation and quantitative assessment of the teachers and teaching classes in various departments are carried out according to the requirements of the school.

The main advantages of the evaluation of the system are: one can realize the distributed system design, reduce the pressure of the server and improve the efficiency of evaluation; two is to evaluate the system department according to the hospital system, to facilitate the organization and management of the departments, improve the quality and reliability of the evaluation, and the three is to reduce the learning through the institutions of various institutions. The work pressure and workload of the school supervision office; four, through the management of the various departments of the school system, the evaluation information of students and teachers can be fed back to the relevant teachers and corresponding class students and counselors in time and effectively, thus promoting the teaching quality and the improvement of the students' management level.

The system mainly includes the following functions: student evaluation, peer review, teacher evaluation, feedback from student information staff, supervision and inspection, teacher workload statistics, system maintenance, etc.

Students' evaluation of teaching mainly realizes the following functions: students log in by name and school number, the system will automatically give all the courses of their teachers, according 
to a variety of ways to quantify the evaluation, and can put forward opinions and suggestions; the system also provides all the details according to the class, and can print and export EXCEL function; press the class Summary, put one class of teachers together, seek the average score of their evaluation, and summarize the opinions and suggestions of each student; according to the teachers' summary, the evaluation information of the class students of the class teacher is summarized; all the teachers in the Department department are collected and counted according to the total summary of the teachers; the system can also be based on the class. The class inquires the evaluation information of each class in each class; the statistics of students' evaluation of teaching can count which classes have participated in the evaluation and which classes do not participate in the evaluation. Each teacher's evaluation content can be sent to every teacher through mailbox, all of which provide online printing and export of Excel functions.

The peer review teaches the teacher to choose his name and enter his own work number to log in. The system will provide all the teachers of the same teaching and research room for evaluation. The system will provide all the teachers of the system department to select which teachers to choose. . The system provides inquiries according to the evaluator, according to the evaluator's inquiries, according to the assessed person's collection, according to the statistics of all the evaluated people, and the statistics of teachers' participation. The above functions provide online printing and import Excel function, and the information can be sent to the corresponding teachers through mailbox.

The teacher's evaluation is made by the teacher's name and work number. The system automatically provides all class classes for evaluation. The system mainly provides the functions such as the evaluation of the students, the class inquiry, the grade inquiry, the statistics of the class, the summary of the class statistics, the summary of the grade, the statistics of the teachers' comments and so on. Functions all provide online printing and import of Excel functions.

The feedback of student information staff mainly includes the feedback information importing of the information clerk, the feedback information inquiry of the information clerks, and the feedback information feedback of the information members (sent automatically through the mailbox).

The teaching routine inspection mainly includes the information about the course, class, teaching location and class number of all the teachers in the week, class, class, class, and so on. Send to relevant teachers), check content entry and other functions.

Teaching material evaluation, teaching teachers and related students are involved in the evaluation of the teaching materials used, the systematic statistics and analysis of teachers and students more satisfactory teaching materials, teachers and students can also recommend materials, and the comprehensive summary of these information for the purchasing staff, the maximum use of teachers and students more satisfactory teaching materials, can improve teachers and students The recognition of textbooks should maximize the role of teaching materials.

System maintenance mainly includes: database backup, data update and personnel information settings.

The system mainly solves the systematicness of the evaluation content, the efficiency of evaluation, the diversity and timeliness of the information feedback, the comparability of the summary statistics and the convenience of the operation, so as to provide a scientific and reliable basis for the management decision of the leadership and the improvement of the teaching quality of the teachers.

\section{Conclusion}

The development and use of the teaching quality evaluation system based on cloud platform greatly improves the efficiency of teaching quality evaluation in Colleges and universities and reduces the cost of manpower and material resources. It has a great effect on improving the teaching management and teaching quality and the teaching level of teachers, and raises the breadth and depth of teaching quality evaluation. Validity and evaluation of real-time information feedback, 
so as to comprehensively promote the automation and informatization of university management.

\section{References}

[1] Yang Xiuping, Zhang Hua, Li Yabing. The construction and guarantee mechanism of the teaching quality evaluation system in Colleges and universities. [J]. laboratory research and exploration, 2018,37 (02): 231-234.

[2] Zhang Yu, Shen Yujie, Duqi Wei. Current situation and Countermeasures of classroom teaching quality evaluation in Colleges and universities [J]. education and teaching forum, 2018 (09): 28-29.

[3] Ruan Mengxun, Shen Liangzhong. Application of association rules in the evaluation of teaching quality in Colleges and universities [J]. computer knowledge and technology, 2018,14 (02): 123-125.

[4] Song Liyan, Liu Xiubo, Zheng Kun. On the construction of the evaluation system of classroom teaching quality in Colleges and universities, [J]. curriculum education research, 2018 (11): 6-7.

[5] Zheng Wanteng, Li Guanghua. Reconstruction of university classroom teaching evaluation index system based on factor analysis [J]. Journal of Weifang engineering Career Academy, 2018,31 (01): 5-9.

[6] Hu Yan, Zhang Liuqing, Wang Zengqiang. Assessment methods of teaching quality of private colleges and universities teachers [J]. modern economic information, 2018 (01): 391-392.

[7] Zhou Jian, Sun Lijuan, Han Chong, Guo Jian, Xiao Fu. Application of meta synthesis method in teaching quality evaluation in higher education [J]. computer education, 2018 (02): 103-106+110.

[8] Fan Yan, Ma Liping. Optimization of BP neural network teaching quality evaluation model [J]. statistics and decision making, 2018,34 (02): 80-82.

[9] Li Weijun, Huang Li Yu. Dynamic evaluation of classroom teaching quality in Colleges and universities. [J]. New Curriculum Research (Journal), 2018 (01): 24-26. 